\title{
Spectroscopy and structural study on CdSe thin films deposited by chemical bath deposition
}

\author{
M. P. Deshpande, Nitya Garg ${ }^{*}$, Sandip V. Bhatt, Pallavi Sakariya, S. H. Chaki \\ Department of Physics, Sardar Patel University, Vallabh Vidyanagar 388120, Gujarat, India \\ *Corresponding author. Tel: (+91) 9687807332; E-mail: nitu5958@yahoo.co.in
}

Received: 29 April 2013, Revised: 28 June 2013 and Accepted: 01 July 2013

\section{ABSTRACT}

Cadmium selenide $(\mathrm{CdSe})$ thin films were prepared by chemical bath deposition technique on glass substrates using cadmium acetate dihydrate as a source of $\mathrm{Cd}^{2+}$ ions, and sodium selenosulphate as a source of $\mathrm{Se}^{2-}$ ions respectively. Triethanolamine and ammonia were used as complexing and $\mathrm{pH}$ controlling agent. Films were deposited at different bath temperatures ranging from room temperature to $80^{\circ} \mathrm{C}$ while the $\mathrm{pH}$ value was kept constant around $10.50 \pm 0.10$. We determined elemental composition of deposited film by X-ray photoelectron spectroscopy. Optical properties of films deposited at different bath temperatures are studied by absorption spectra and parameters like thickness, band gap and absorption coefficient were calculated from the optical transmission spectra. The optical spectra showed a small blue shift and the band gap was found to be greater than the bulk phase. Raman measurements performed at room temperature using Helium-neon laser and Argon laser confirmed the presence of longitudinal optical phonon modes. The selected area electron diffraction pattern for CdSe thin films indicated that they are having mixed nature i.e. both single crystalline and polycrystalline nature with planes of diffraction rings corresponding to cubic structure of CdSe respectively. Copyright (C) 2013 VBRI press.

Keywords: Semiconductor; chemical bath deposition; X-ray photoelectron spectroscopy; optical spectroscopy.

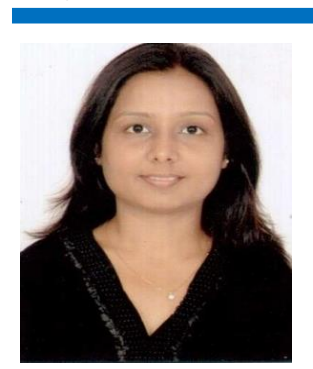

Nitya Garg received her Ph.D. degree from Department of Physics, Sardar Patel University in 2013 in the field of Synthesis and characterization of semiconductor nanomaterials. At present she is working as regular lecturer at govt. polytechnic college, Surat, India.

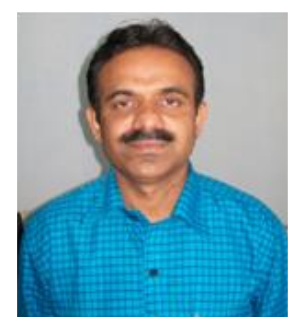

M.P. Deshpande did his Ph.D. in the field of crystal growth and characterization in the year 1998 from Department of Physics, Sardar Patel University, Vallabh Vidyanagar, Gujarat, India. At present he is involved in the field of synthesis of metal and semiconductor nanomaterials by chemical route and their application in antimicrobial activity. Apart from this he is also doing the work in the field of Raman Spectroscopy of different layered semiconductors at high pressures using diamond anvil cell.

\section{Introduction}

During the past few decades, there has been increasing interest in the deposition and characterization of II-VI group semiconductor compound ( $\mathrm{ZnSe}, \mathrm{CdS}, \mathrm{CdTe}, \mathrm{CdSe}$ etc.) thin films because of their wide application in various fields of optoelectronic technology. Among II-VI group, $\mathrm{CdSe}$ is considered to be a potential candidate for various applications such as solar cells, thin film transistors, sensors, lasers, photoconductors, gamma ray detectors [13], and photoelectrochemical cells [4] because of having high efficiency of radiative recombination, high absorption coefficient, high photosensitivity, direct band gap corresponding to a wide spectrum of wavelengths from ultraviolet to infrared regions [5-7] and quantum size effect [8]. A variety of techniques have been used for the deposition of thin films and among all methods, chemical bath deposition (CBD) is being largely investigated as a convenient and low-cost technique for producing large-area thin films of semiconducting materials. Advantages of this technique includes requirement of very simple equipment, does not require high temperature or pressure, less incorporation of impurities, deposition of multicomponent chalcogenide thin films over a wide range of stoichiometry, high reproducibility, environment friendly, scope of converting intrinsic semiconductors to n-type or p-type and control of film thickness or stoichiometry by the optimization of various deposition conditions like temperature, time, concentration of reactants, complexing 
salt concentration etc. Film formation is truly a deposition of compound rather than a co-deposition of separate elements and is uniquely suited for deposition of a uniform film over large substrates of complex geometries. This technique is quite safe because it involve reactants which are not in the vapour phase. It is well known that toxicity hazards associated with lead, cadmium, mercury, selenium, etc. are severe when inhaled which can be avoided in this method. Besides, the above mentioned advantages, much utility of this technique lies with the fact that in this technique, wastage of solution can be minimized since the obtained precipitate is usually stoichiometric and of high purity which can be further reused as starting material for other deposition techniques.

CBD technique was used by several researchers for the deposition of CdSe thin films [9-11]. Literature survey shows that extensive work has been done on the preparation of CdSe thin films, but very few workers deposited these films using triethanolamine (TEA) as complexing agent having cubic structure or single phase at low temperature [12-15]. Moreover, little attention has been paid in studying the properties of CdSe thin films deposited at different bath temperatures. Till today most of the study is on CdSe thin film deposited at room temperature. The novelty of current work lies in studying various properties like elemental, structural, vibrational and optical properties of CdSe thin films deposited at different bath temperatures by X-ray photoelectron spectroscopy (XPS), Selected area electron diffraction (SEAD), Raman spectroscopy and UV-Vis-NIR spectroscopy because all these properties are very sensitive to deposition conditions and hence, its study with respect to ambient conditions is a matter of high importance. In view of this, the present study deals with preparation and characterization of $\mathrm{CdSe}$ thin films at different bath temperatures by CBD method on glass substrates using TEA as complexing agent. The elemental, structural and optical properties of deposited $\mathrm{CdSe}$ films have been studied and the results are discussed in detail.

\section{Experimental}

\section{Materials}

The chemicals used for the preparation were analytical grade cadmium acetate dihydrate $\left[\left(\mathrm{CH}_{3} \mathrm{COO}\right)_{2} \mathrm{Cd} .2 \mathrm{H}_{2} \mathrm{O}\right]$ (99\%) purchased from Himedia Lab Pvt. Ltd., Mumbai, selenium powder ( $\mathrm{Se})(99.9 \%)$ purchased from Alfa Aesar, Hyderabad, triethanolamine (TEA) $\left[\mathrm{N}\left(\mathrm{CH}_{2} \mathrm{CH}_{2} \mathrm{OH}\right)_{3}\right]$ (98\%) purchased from Sisco Chem. Pvt. Ltd, Mumbai, sodium sulphite $\left(\mathrm{Na}_{2} \mathrm{SO}_{3}\right)$ (98\%) purchased from Alfa Aesar, Hyderabad and ammonia hydroxide $\left(\mathrm{NH}_{3} \mathrm{OH}\right)$ (25\%) purchased from Chiti-Chem Corporation, Baroda. Commercially available glass microslides were used as a substrate for deposition of thin films, kept in chromic acid for 6-7 $\mathrm{h}$, washed with detergent, rinsed in acetone and finally ultrasonically cleaned with double distilled water.

\section{Deposition of CdSe thin films}

The CdSe thin films were deposited on glass substrates from an aqueous alkaline solution containing cadmium salt in complex form and selenide ions. The deposition process is described in literature $[\mathbf{1 5}, \mathbf{1 6}]$ and its underlying deposition principle is discussed in literature [17]. The chemical deposition is based on the slow release of $\mathrm{Cd}^{2+}$ and $\mathrm{Se}^{2-}$ ions in the basic solution and the subsequent condensation of these ions on the substrate suitably mounted in the bath. TEA is used in combination with ammonia to control the release of the metal ions from their precursor solutions resulting in the formation of a homogenous thin film on the substrate. The deposition was carried out at different bath temperatures ranging from room temperature $(\mathrm{RT})$ to $80^{\circ} \mathrm{C}$ at an optimum $\mathrm{pH}(10 \pm$ $0.50)$.

\section{Characterization}

The chemical composition of deposited film was studied using X-ray photoelectron spectroscopy (XPS) (ModelVSW ESCA) taken at chamber vacuum of $10^{-9}$ torr using monochromatic $\left(\mathrm{Al} \mathrm{K}_{\alpha}\right)$ X-ray radiation as the exciting source having $44 \mathrm{eV}$ pass energy. Selected area electron diffraction (SEAD) pattern images were obtained using a Tecnai 20 Philips, Holland electron microscope operated at an accelerating voltage of $200 \mathrm{kV}$ and current $3.42 \mu \mathrm{A}$. For this, thin films of $\mathrm{CdSe}$ were scratched from glass substrates using diluted HF acid and taken on carbon replica placed on a copper grid. The Raman spectrums were taken at room temperature using Raman spectrometer (Model Jobin -Yvon Horiba LABRAM HR 800) by exciting the sample with $632 \mathrm{~nm}, 5 \mathrm{~mW}$ He-Ne laser and $488 \mathrm{~nm}, 10 \mathrm{~mW}$ Argon laser in the region between 100-700 $\mathrm{cm}^{-1}$ with a measurement time of $8 \mathrm{sec}$ and $120 \mathrm{sec}$ respectively. The room temperature optical spectra were recorded in the wavelength range $200-1000 \mathrm{~nm}$ using UVVis-NIR spectrophotometer (Perkin Elmer Lambda 19).

\section{Results and discussion}

The basic principle behind depositing CdSe thin films by chemical bath deposition technique involves the controlled precipitation of CdSe compound on glass substrates from a solution containing cadmium acetate dihydrate, sodium selenosulphate, TEA and ammonia. Precipitation of the solid phase occurs due to the supersaturation in the reaction bath. At a given temperature when ionic product of reactants exceeds the solubility product, precipitation occurs. Whereas, if the ionic product is less than the solubility product, then the solid phase produced will dissolve back to the solution resulting in no net precipitation. The free metal ion concentration is controlled by the temperature, $\mathrm{pH}$ of the reaction bath and concentration of complexing agent. The growth rate of the film depends on the relative concentration of $\mathrm{Cd}^{2+}$ and $\mathrm{Se}^{2-}$ ions in the reaction mixture. By controlling this parameter uniform films of desired thickness can be grown. In our work, a complexing agent (TEA) is used in a solution to control the hydrolysis of the cadmium metal ion. The free $\mathrm{Cd}^{2+}$ ion concentration is controlled by the formation of complex species according to the general reaction.

Cadmium salt reacted with $\mathrm{N}\left(\mathrm{CH}_{2} \mathrm{CH}_{2} \mathrm{OH}\right)_{3}$ (TEA) to form complex Cd salt,

$\mathrm{Cd}^{2+}+\mathrm{TEA} \longrightarrow[\mathrm{Cd}(\mathrm{TEA})]^{2+}$ 
Hydrolysis of ammonia in water gives $\mathrm{OH}^{-}$ions in solution according to the equation,

$\mathrm{NH}_{3}+\mathrm{H}_{2} \mathrm{O} \leftrightarrow \mathrm{NH}_{4}^{+}+\mathrm{OH}^{-}$

Finally formation of CdSe thin films takes place via the chemical reaction,

$[\mathrm{Cd}(\mathrm{TEA})]^{2+}+\mathrm{Na}_{2} \mathrm{SeSO}_{3}+2 \mathrm{OH}^{-} \longrightarrow \mathrm{CdSe}+\mathrm{Na}_{2} \mathrm{SO}_{4}$ $+\mathrm{TEA}+\mathrm{H}_{2} \mathrm{O}$

\section{Chemical composition study by XPS}

In order to verify the elemental composition of deposited CdSe films, the XPS spectra was taken and is shown in Fig. 1 corresponding to individual elements of the CdSe thin film deposited at RT. The binding energies measured in the XPS analysis were corrected for specimen charging by referencing the $\mathrm{C} 1 \mathrm{~s}$ to $284.6 \mathrm{eV}$. The figure exhibits the detailed spectra corresponding to individual elements of CdSe film respectively. The strong peaks at 411.5, 404.8 and $10.1 \mathrm{eV}$ corresponds to $\mathrm{Cd} 3 \mathrm{~d}_{3 / 2}, \mathrm{Cd} 3 \mathrm{~d}_{5 / 2}$ and $\mathrm{Cd} 4 \mathrm{~d}_{5 / 2}$ binding energies. The peak at $52.9 \mathrm{eV}$ measured in the $\mathrm{Se}$ energy region is attributed to the Se3d transition. These results are close to that of bulk CdSe [18] and matches with the reported results [19]. The small shift in the binding energy of Se from their standard values is due to the presence of adsorbed oxygen and no impurities peaks are observed on the surface.
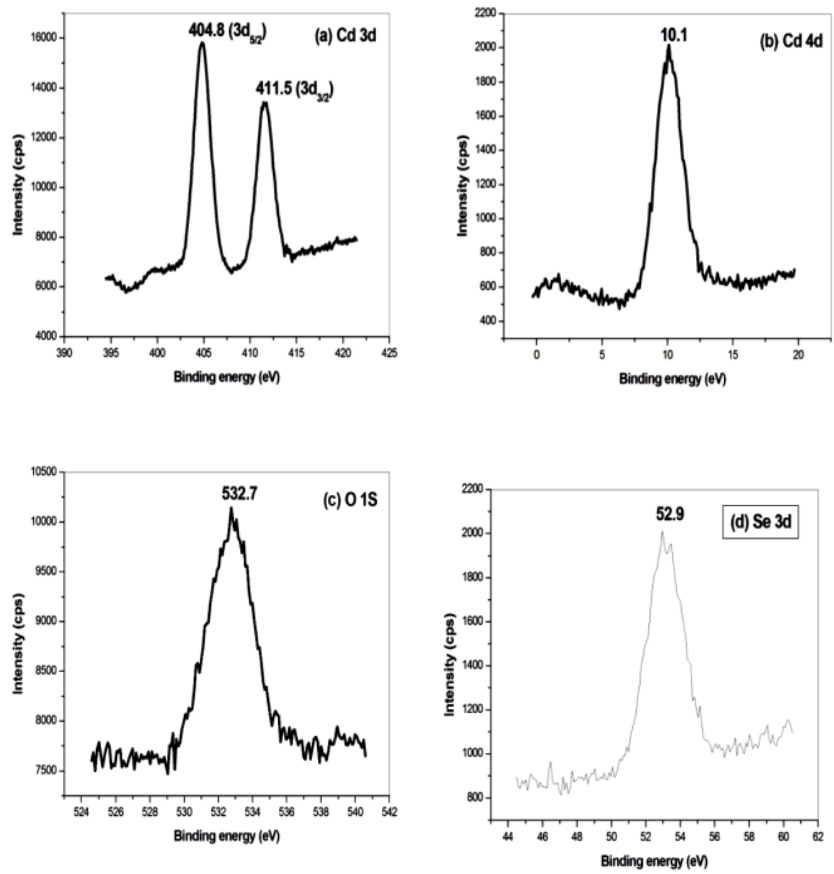

Fig. 1. XPS Spectra corresponding to individual elements [(a) Cd 3d (b) Cd 4d (c) O 1S (d) Se 3d] of the CdSe thin film deposited at RT.

Structural study by selected area electron diffraction pattern (SAED)

Fig. 2(a) and 2(b) shows typical selected area diffraction patterns of the CdSe thin films deposited at RT and $80^{\circ} \mathrm{C}$ obtained using Transmission electron microscope (TEM). Presence of spots and rings in selected area electron diffraction patterns (SAED) confirms that the corresponding regions of deposited $\mathrm{CdSe}$ thin films are having mixed behaviour i.e. polycrystalline and single crystalline in nature. Knowing electron beam wavelength $\lambda$, values of interplanar spacing (d) corresponding to all diffraction rings have been calculated from the following equations and are shown in Table 1.

Table 1. TEM analysis for CdSe thin films deposited at RT and $80^{\circ} \mathrm{C}$.

\begin{tabular}{cccccccc}
\hline Sample & $\begin{array}{c}\text { Ring } \\
\text { No. }\end{array}$ & $\begin{array}{c}\text { Diameter of } \\
\text { Ring }(\mathbf{m m})\end{array}$ & $\begin{array}{c}\text { Interplanar } \\
\text { spacing } \\
(\boldsymbol{A})\end{array}$ & $\begin{array}{c}\text { Standard } \\
\text { d values } \\
(\boldsymbol{A})\end{array}$ & & & $\begin{array}{c}\text { (hkl) } \\
\text { Nattice } \\
\text { Parameter } \\
\mathbf{a}(\boldsymbol{A})\end{array}$ \\
\hline $\mathrm{RT}$ & 1 & 9.5 & 1.845 & 1.833 & $(311)$ & 11 & 6.119 \\
& 2 & 15 & 1.169 & 1.169 & $(511)$ & 27 & 6.072 \\
& 3 & 18 & 0.973 & 0.961 & $(620)$ & 40 & 6.159 \\
$80^{\circ} \mathrm{C}$ & 1 & 12 & 1.461 & 1.519 & $(400)$ & 16 & 5.843 \\
& 2 & 15 & 1.169 & 1.169 & $(511)$ & 27 & 6.072 \\
& 3 & 21 & 0.834 & 0.851 & $(551)$ & 51 & 5.961 \\
\hline
\end{tabular}

$\lambda=\sqrt{\frac{1.5}{V}} \mathrm{~nm}$

$\mathrm{d}=\frac{2 \lambda \mathrm{L}}{\text { Ring diameter }} \AA$

where $\mathrm{V}$ is the accelerating potential of the electron beam $(=200 \mathrm{kV})$ and $\mathrm{L}$ is the distance between photographic film and the specimen which was kept $320 \mathrm{~mm}$ during measurement. From Table 1 it is clear that the measured lattice spacing of the lattice plane matches well with the zinc-blende structure of CdSe. This confirms that the deposited films possess cubic structure.

The lattice parameter was calculated from the equation:

$\mathrm{a}=\mathrm{d}\left(\mathrm{h}^{2}+\mathrm{k}^{2}+\mathrm{l}^{2}\right)^{1 / 2}$

where ' $\mathrm{a}$ ' is the lattice parameter and $\mathrm{h}, \mathrm{k}$ and $\mathrm{l}$ are the Miller indices and $d$ is the interplanar spacing for the plane (h k l). The calculated lattice parameter 'a' (Table 1) for CdSe thin films deposited at RT and $80^{\circ} \mathrm{C}$ from TEM shows slight variation with the JCPDS results [20].

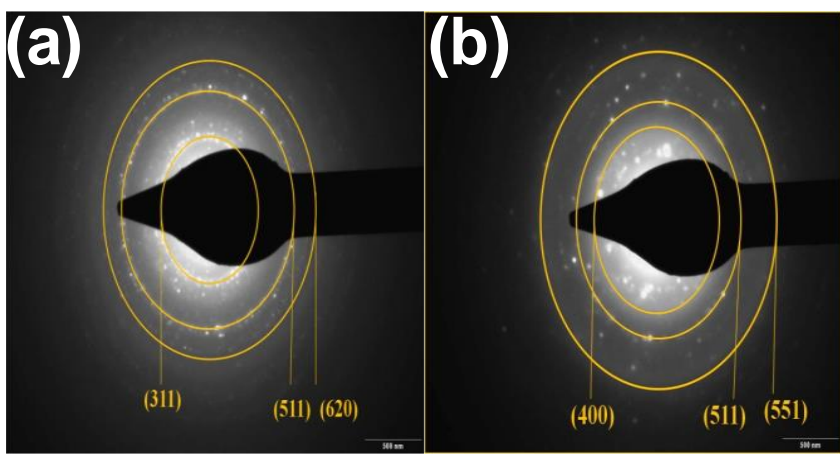

Fig. 2. Selected area electron diffraction pattern (SAED) images of CdSe thin films deposited at (a) RT and (b) $80^{\circ} \mathrm{C}$ 


\section{Raman spectroscopy}

Fig. 3 (a) and 3(b) shows the Raman spectra of CdSe thin films deposited at different bath temperatures on glass substrates recorded by exciting the sample with He-Ne laser and Argon laser respectively. The peaks obtained in Raman spectrum in all samples corresponds to first order and second order longitudinal optical phonons which has a close resemblance with the reported values [21]. Second overtone of LO phonon mode is observed with decreasing intensity. It is well known that the higher the intensity of the overtone, the better crystalline structure of the films. The position of the LO and 2LO peaks can be compared to the bulk CdSe which exhibits the first LO and 2LO Raman peak at $210 \mathrm{~cm}^{-1}$ and $418 \mathrm{~cm}^{-1}$ [22]. The small $3-5 \mathrm{~cm}^{-1}$ of Raman shift for LO and 4-6 $\mathrm{cm}^{-1}$ for $2 \mathrm{LO}$ phonon frequency may be due to the quantum confinement of phonon mode or strain developed in CdSe layers during deposition.
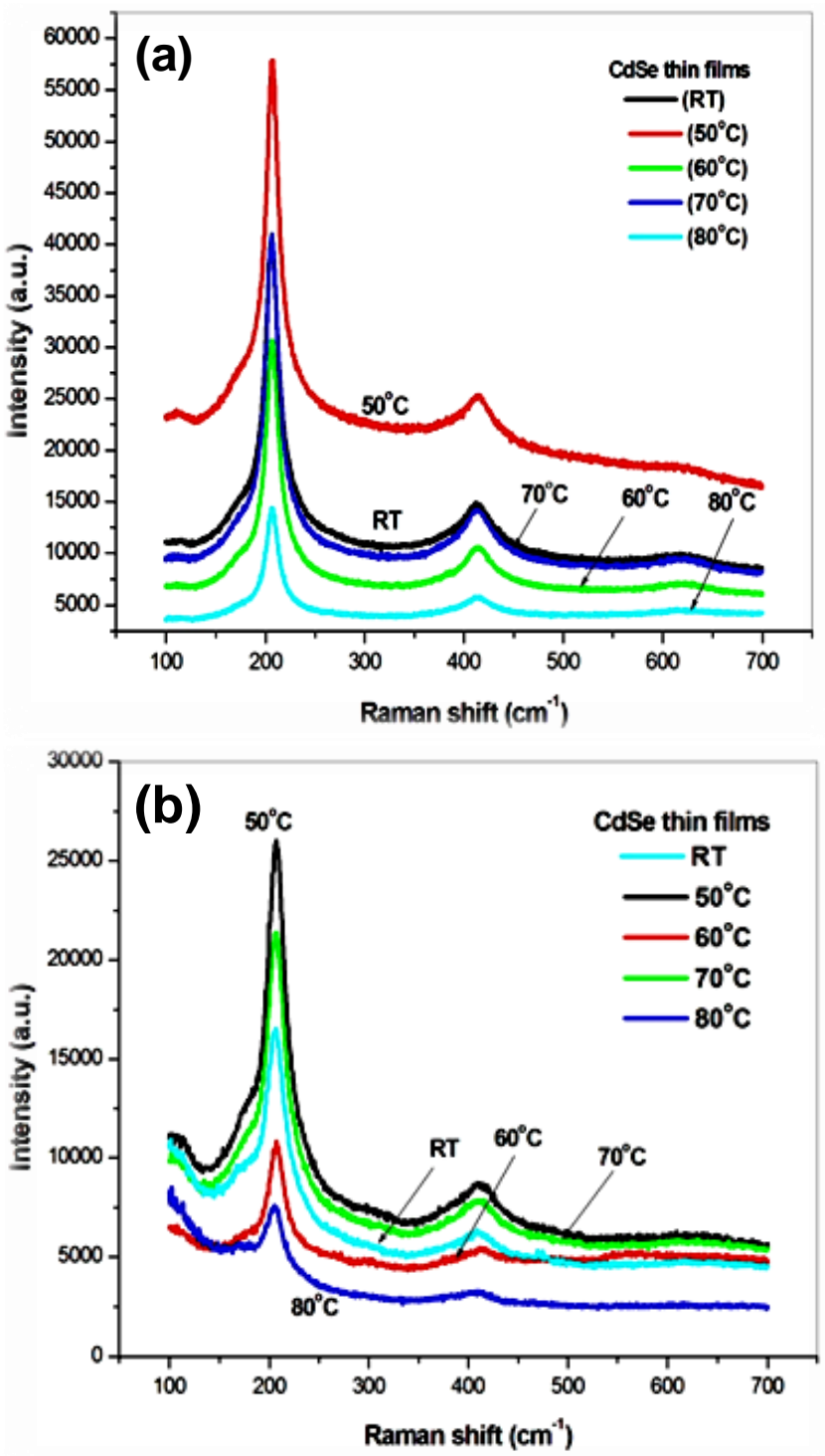

Fig. 3. Raman Spectra of CdSe thin film at different bath temperatures from RT to $80^{\circ} \mathrm{C}$ (a) Helium-neon Laser $(\lambda=632 \mathrm{~nm}, 5 \mathrm{~mW})$ (b) Argon Laser $(\lambda=488 \mathrm{~nm}, 10 \mathrm{~mW})$.

Intensity comparison shows that the Raman effects are stronger when He-Ne laser is used for the excitation.
Excitation with $\mathrm{He}-\mathrm{Ne}$ laser corresponds to better resonance conditions because energy of the laser is close to the bandgap of $\mathrm{CdSe}$ thin films compared to excitation with Argon laser.
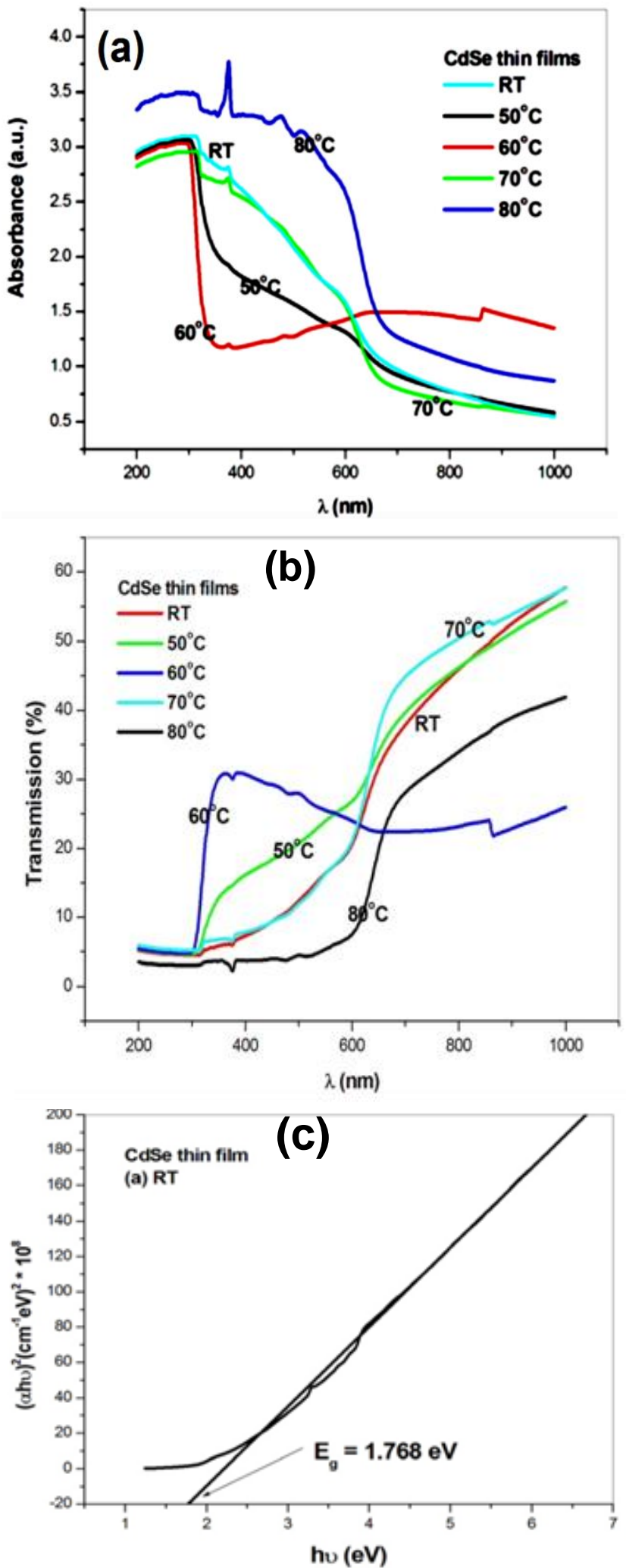

Fig. 4. (a) Optical absorbance versus wavelength (b) Optical transmission versus wavelength plot at different bath temperatures (c) Plot of $(\alpha h v)^{2}$ Versus $(h v)$ at RT. 
$U V$-VIS spectroscopy

Room temperature optical absorption and transmittance spectra of CdSe thin films deposited at different bath temperatures on glass substrates are shown in Fig. 4(a) and 4(b). All the films show an increasing absorbance in the ultraviolent and visible region. Films prepared at higher bath temperature $\left(80^{\circ} \mathrm{C}\right)$ have higher absorption values as compared with other bath temperatures. This is due to the fact that film deposited at $80^{\circ} \mathrm{C}$ has the better crystallinity compared with film deposited at RT. The study of absorption spectra reveals the presence of absorption edge having distinct positions of different broadening with different bath temperatures and are blue shifted compared to their bulk counterpart which lies at $713 \mathrm{~nm}$ indicating the influence of size quantization $[12,14]$. A plot of $(\alpha h v)^{2}$ versus $(h v)$ for CdSe thin film at room temperature is plotted and shown in Fig. 4(c), where $\alpha$ is the optical absorption coefficient, computed from the transmittance data. Similar plots have been obtained for other temperatures also. Extrapolating the straight-line portions of the plot for zero absorption coefficient value gives the ' $E_{g}$ ' for the deposited $\mathrm{CdSe}$ thin films and confirms that material is a semiconductor with a direct band gap. The band gap values are greater than the bulk crystalline value $(1.74 \mathrm{eV})[23]$.

Table 2. Parameters calculated from optical spectra.

\begin{tabular}{cccccc}
\hline $\begin{array}{l}\text { Sample } \\
(\mathrm{CdSe}\end{array}$ & \multicolumn{5}{c}{$\mathrm{E}_{\mathrm{g}}(\mathrm{Bulk})=1.74 \mathrm{eV}, \lambda=713 \mathrm{~nm}$} \\
\cline { 2 - 6 } $\begin{array}{l}\text { thin } \\
\text { films })\end{array}$ & $\mathrm{E}(\mathrm{eV})$ & $\begin{array}{c}\text { Particle } \\
\text { diameter } \\
(\mathrm{nm})\end{array}$ & $\lambda(\mathrm{nm})$ & $\begin{array}{c}\Delta \mathrm{E}_{\mathrm{g}} \\
=\mathrm{E}-\mathrm{E}_{\mathrm{g}} \\
(\mathrm{eV})\end{array}$ & $\begin{array}{c}\text { Film } \\
\text { thickness } \\
\mathrm{d}(\mu \mathrm{m})\end{array}$ \\
\hline $\mathrm{RT}$ & 1.768 & 27.19 & 700 & 0.028 & 1.369 \\
$50^{\circ} \mathrm{C}$ & 3.584 & 3.583 & 345 & 1.844 & 1.219 \\
$60^{\circ} \mathrm{C}$ & 3.758 & 3.425 & 329 & 2.018 & 0.3454 \\
$70^{\circ} \mathrm{C}$ & 1.835 & 12.82 & 674 & 0.095 & 1.058 \\
$80^{\circ} \mathrm{C}$ & 1.994 & 7.692 & 620 & 0.254 & 0.8474 \\
\hline
\end{tabular}

It is known that such shift to higher energies of the optical bandgap arises from very small grain and the resulting quantum confinement of electronic states in the thin films [24]. For average grain radius the shift in $E_{g}$ is $0.38 \mathrm{eV}$ to $0.51 \mathrm{eV}$ in chemically room temperature deposited CdSe thin films have been reported [12], whereas in our case we have obtained the shift of $0.028 \mathrm{eV}$ at RT. Values of absorption edge wavelength, energy band gap and band energy shift of all CdSe thin films deposited at different bath temperatures are shown in Table 2.

The thickness (d) of the films was calculated from the transmission spectra using equation reported in literature [25]. From the transmission data, nearly at the fundamental absorption edge, the values of absorption coefficient $(\alpha)$, are calculated in the region of strong absorption using the relation;

$$
\alpha=\frac{\ln \left(\frac{1}{T}\right)}{d}
$$

The average radius of $\mathrm{CdSe}$ grain can be estimated from the effective mass approximation [26] by taking effective mass of electron and hole as $m_{e}^{*}=0.13 m_{0}$ [27] and $m_{h}^{*}=0.44$ [28], we calculated values of particle diameter which are shown in Table 2.

From Table 2, it was found film thickness decreases with the increase of bath temperature. The grain sizes of $\mathrm{CdSe}$ films were varied by depositing films of different thicknesses.

\section{Discussion}

The quality of deposited film plays an important role in photovoltaic device performance. CBD deposited films are thin, transparent, uniform, adherent, compact to the substrate with fewer flaws and form stable interface with other absorbing layers thereby fulfill the criteria required for the processing of CdSe based solar cells or thin film transistors [29, 30]. Although other techniques like electrodeposition, vacuum evaporation, and molecular beam epitaxy have been reported for the better deposition of CdSe thin films but CBD method is the most popular one. Because it is cost-effective and large area substrates can be coated for practical applications. Moreover, most of film deposition techniques reported the formation of $\mathrm{CdSe}$ thin films at high temperatures having hexagonal structure containing elemental or substrate impurities [31] whereas, our X-ray diffraction (Xrd) result confirmed that deposited films are of pure CdSe compound having cubic structure because no Xrd peak corresponding to elemental cadmium, selenium or substrate is observed [16] as reported in films deposited on stainless steel by electrodeposition technique [32] thereby suggesting CBD deposited films are well covered to the substrate. Literature review shows that films deposited by thermal evaporation and electrodeposition are mostly non stoichiometric [33, 34] whereas our result shows formation of nearly stoichiometric CdSe film [16]. It was reported that SAED of CdSe thin film deposited by electrodeposition technique for $500 \mathrm{sec}$ do not show distinct rings or spots indicating formation of amorphous film [35] whereas, CBD deposited films show crystalline nature. Existing literature indicated that $\mathrm{CdSe}$ film deposited by photochemical deposition (PCD) shows presence of carbon as impurity in XPS spectra. Also its Raman spectra taken using Argon laser show only one longitudinal optical (LO) mode at frequency shift of $210 \mathrm{~cm}^{-1}$ having full width at half maximum (FWHM) significantly more than CBD deposited films indicating less crystalline structure [36]. Presence of large LO overtones, is an evidence of good crystalline quality of the samples. A surface-optic Raman mode has been observed for CBD deposited films [37] whereas in our samples no surface-optic Raman mode was present. This is also another indication of the good crystalline quality of our samples.

\section{Conclusion}

From above studies, it is concluded that chemical bath deposition technique can be successfully employed for the preparation of $\mathrm{CdSe}$ thin films on glass substrates at different bath temperatures ranging from RT to $80^{\circ} \mathrm{C}$. Elemental composition of deposited film was studied with 
XPS. The spot and ring pattern in SAED confirms that the deposited CdSe films are having mixed nature i.e. both single crystalline and polycrystalline nature and diffracted ring planes are representative of the cubic structure of CdSe. Raman spectra measurements showed the presence of LO and 2LO phonon peaks. The optical study shows that the CdSe thin films possess direct allowed transition. The band gap value of CBD deposited films is higher than that of the bulk phase value.

\section{Acknowledgements}

We are grateful to Dr. Vasant G. Sathe, Dr. T. Shripathi, UGC-DAE (CSR), Indore for helping in obtaining Raman \& XPS spectra. We also acknowledge SICART, V. V. Nagar for assisting us in TEM and UV-VIS spectrophotometer characterization of our samples.

\section{Reference}

1. Khomane, A. S.; Hankare, P. P. J. Alloys Comp. 2010, 489, 605 DOI: $10.1016 /$ j.jallcom.2009.09.122

2. Sathyalatha K. C.; Uthanna S.; Reddy P. J. Thin Solid Films. 1989, 174, 233.

DOI: $10.1016 / 0040-6090(89) 90895-X$

3. Yadav A. A.; Barote M. A.; Masumdar E. U. Mater. Chem. Phys. 2010, 121, 53 .

DOI: $10.1016 /$ j.matchemphys.2009.12.039.

4. Farva U.; Park C. Sol. Energ. Mat. Sol. Cells. 2010, 94, 303. DOI: $10.1016 /$ j.solmat.2009.10.003

5. Razykov T. M. Thin Silid Films. 1988, 164, 301. DOI: $10.1016 / 0040-6090(88) 90153-8$

6. Sutrave, D. S.; Shahane, G. S.; Patel, B. B.; Deshmukh, L. P. Mater. Chem. Phys. 2000, 65, 298.

DOI: $10.1016 / \mathrm{S} 0254-0584(00) 00240-6$

7. Deshmukh, L. P.; More, B. M.; Holikatti, S. G.; Hankare, P. P. Bull. Mater. Sci. 1994, 17, 455.

DOI: $\underline{10.1007 / \mathrm{BF} 02757889}$

8. Murray, C. B.; Kagan, C. R.; Bawendi, M. G. Science. 1995, 270, 1335. DOI: $10.1126 /$ science. 270.5240 .1335

9. Chate, P. A; Sathe, D. J; Hankare, P. P; Lakade S. D; Bhabad, V. D. J. Alloys Comp. 2013, 552, 40.

DOI: $10.1016 /$ j.jallcom.2012.10.012

10. Bakiyaraj, G; Dhanasekaran, R. Cryst. Res. Technol. 2012, 47, 960. DOI: $10.1002 /$ crat.201200196

11. Gopakumar, N; Anjana, P. S; Vidyadharan Pillai, P. K. J. Mater. Sci. 2010, 45,6653

DOI: $10.1007 / \mathrm{s} 10853-010-4756-1$

12. Mehta, C.; Abbas, J. M.; Saini, G. S. S.; Tripathi, S. K. Chalcogenide Lett. 2007, 4, 133.

13. Das, R.; Sahu, P. K. J. Optoelectron Adv. Mater. 2010, 12, 1406.

14. Erat, S.; Metin, H.; Ari, M. Mater. Chem. Phys. 2008, 111, 114. DOI: $10.1016 / \mathrm{j}$. matchemphys.2008.03.021

15. Mondal, A. A.; Chaudhuri, T. K.; Mondal, P. P. Sol. Energ. Mater. 1983, 7, 431 .

16. Deshpande, M. P.; Garg, N.; Bhatt, S. V.; Sakariya, P.; Chaki, S. H. Mat. Sci. Semicon. Proc. 2013, 16, 915.

DOI: $10.1016 / \mathrm{j} . \mathrm{mssp} .2013 .01 .019$

17. Chopra, K. L; Das, S. R. Thin film solar cells; Plenum Press: New York, London, 1983, pp. 283.

18. Polak, M. J. Electron Spectrosc. 1982, 28, 171.

DOI: $10.1016 / 0368-2048(82) 85040-8$

19. Ichimura, M.; Takeuchi, K.; Nakamura, A.; Arai, E. Thin Solid Films. 2001, 384, 157.

DOI: $10.1016 / \mathrm{S} 0040-6090(00) 01826-5$

20. JCPDS File No: $19-0191$

21. Kale, R. B.; Sartale, S. D.; Chougule, B. K.; Lokhande, C. D. Semicond. Sci. Tech. 2004, 19, 980.

DOI: $10.1088 / 0268-1242 / 19 / 8 / 006$

22. Xi, L.; Lam, Y. M.; Xu, Y. P.; Li, L.-J. J. Colloid Interf. Sci. 2008, $320,491$.

DOI: $10.1016 /$ j.jicis. 2008.01 .048

23. Sze, S. M. Physics of semiconductor devices; $2^{\text {nd }}$ Ed., John Wiley and Sons Inc: Newyork, 1981, pp. 848.

DOI: $\underline{10.1002 / 9780470068328}$
24. Moskovits, M. In Chemical physics of atomic and molecular clusters; Soles, G. (Ed.); Amsterdam, North Holland, 1990, pp. 397.

25. Pankove, J. I. Optical Processes in Semiconductors; Dover Publications Inc.: New York, 1975.

26. Kulish, N. R.; Kunets, V. P.; Lisitsa, M. P. Phys. Solid State. 1997, $39,1667$. DOI: $10.1134 / 1.1130216$

27. Cohen, E.; Sturge, M. D. Phys. Rev. B. 1982, 25, 3828. DOI: $10.1103 /$ PhysRevB.25.3828

28. Trallero-Giner, C.; Debernardi, A.; Cardona, M.; Menendez-Proupin, E.; Ekimov, A. I. Phys. Rev. B. 1998, 57(8), 4664. DOI: $10.1103 /$ PhysRevB.57.4664

29. Gan, F. Y; Shih I. IEEE T. Electron Devices. 2002, 49, 15. DOI: $10.1109 / 16.974742$

30. Mahawala, P; Vakkalanka, S., Jeedigunta, S., Ferekides, C. S., Morel D. L. $31^{\text {st }}$ IEEE conference on Photovoltaic Specialist. 2005, 418. DOI: $10.1109 /$ PVSC.2005.1488158

31. Lokhande; C. D; Lee, E.-H; Jung, K.-D; Joo, O.-S. Mater. Chem. Phys. 2005, 91, 399.

DOI: $10.1016 /$ i.matchemphys.2005.03.051

32. Gudage, Y. G; Deshpande, N. G; Sagade, A. A; Sharma, R. P; Pawar, S. M; Bhosale, C. H. Bull. Mater. Sci., 2007, 30, 321. DOI: $10.1007 / \mathrm{s} 12034-007-0053-2$

33. Devadason, S; Muhamad M. R. Physica B. 2007, 393, 125. DOI: $10.1016 / \mathrm{j}$. physb.2006.12.073

34. S.M. Pawar, S. M; Moholkar, A. V; Bhosale, C. H. Mater. Lett. 2007, 61, 1034 DOI: $10.1016 /$ j.matlet.2006.06.044

35. Shaikh, A. V; Mane, R. S; Pathan, H. M; Min, B.-K; Joo, O.-S; Han, S.-H. J. Electroanal. Chem. 2008, 615, 175 . DOI: $\underline{10.1016 / \mathrm{j} . j \mathrm{jelechem} .2007 .12 .009}$

36. Ichimura, M; Takeuchi, K; Nakamura, A; Arai, E. Thin Solid Films. 2001, 384, 157 DOI: $10.1016 / \mathrm{S} 0040-6090(00) 01826-5$

37. Rai, B. K.; Bist, H. D; Katiyar; R. S; Nair, M. T. S; Nair, P.K; Mannivannan, A. J. Appl. Phys. 1997, 82, 1310

DOI: $10.1063 / 1.365904$

\section{Advanced Materials Letters}

Publish your article in this journal

ADVANCED MATERIALS Letters is an international journa published quarterly. The journal is intended to provide top-quality peer-reviewed research papers in the fascinating field of materials
science particularly in the area of structure, synthesis and processing, characterization, advanced-state, properties, and proplications of materials. All articles are indexed on varios databases including DOA and are avaliable for download for free. The manuscript management system is completely electronic and has fast and fair peer-review process. The journal includes review articles, research articles, notes, letter to editor and short communications.

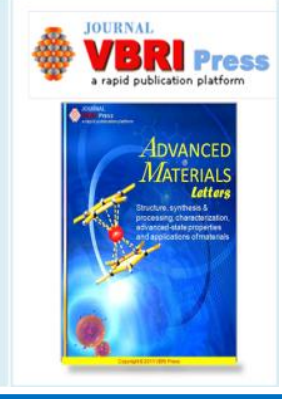

